\title{
Images
}

\section{Unexpected source of fever: Liver abscess on point-of-care ultrasound}

\section{Diphile Iradukunda, MD, CCFP (EM)*; Jonathan Lee, $\mathrm{MD}^{\dagger}$; Daniel J. Kim, MD, FRCPC}

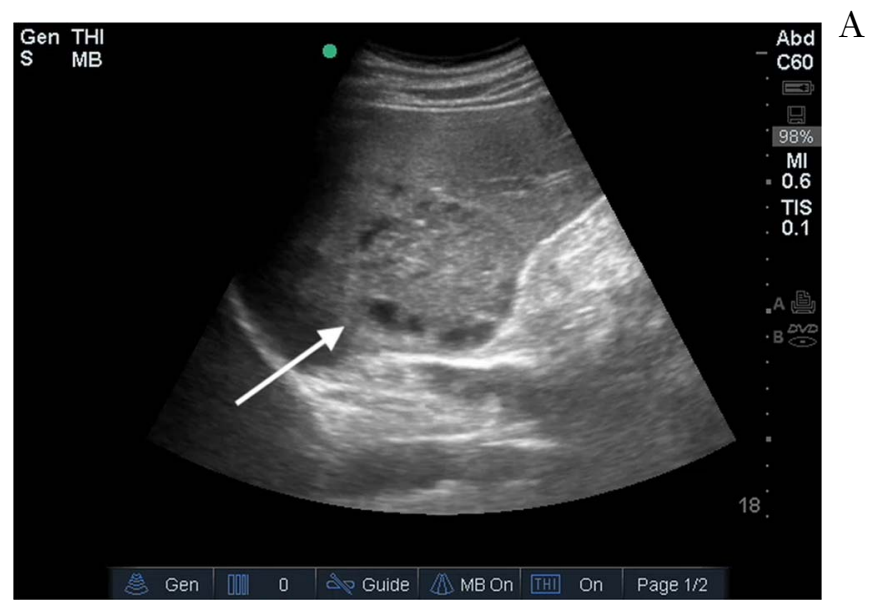

Figure 1. Ultrasound image of the well-circumscribed abscess (arrow) containing multiple cystic hypoechoic collections and heterogeneous material with similar echogenicity to surrounding liver parenchyma.

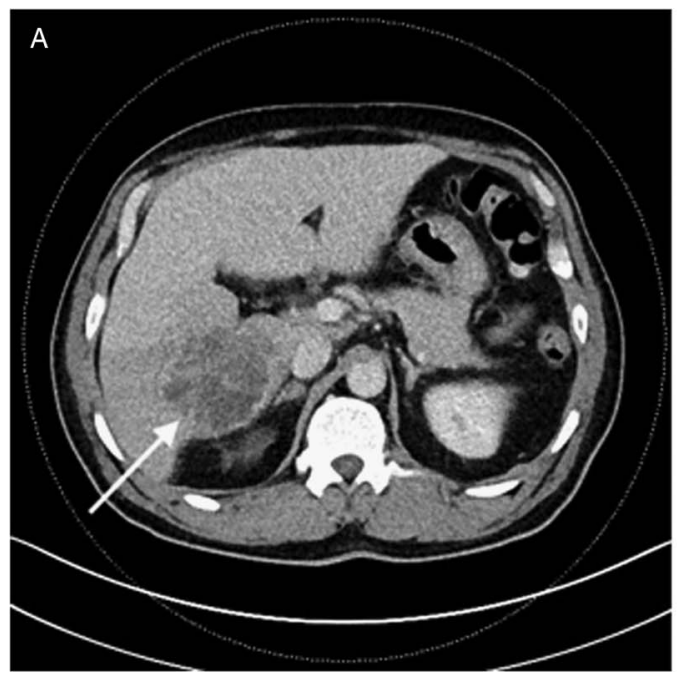

previously healthy 58 -year-old male presented to the emergency department with a 1-week history of fever and abdominal pain. Initial laboratory investigations demonstrated an elevated white blood cell count and transaminasemia. Point-of-care ultrasound (POCUS) was performed to assess for gallbladder pathology; it unexpectedly identified a $7 \mathrm{~cm} \times 6 \mathrm{~cm} \times 6 \mathrm{~cm}$ heterogeneous mass within the liver (Figure 1, Supplementary Video 1). A subsequent computed tomography scan suggested the mass to be a liver abscess (Figure 2A and 2B). It was later percutaneously aspirated under ultrasound guidance and grew Klebsiella pneumoniae. The patient was successfully treated with a 6-week course of intravenous ceftriaxone.

Liver abscesses appear primarily hypoechoic with some internal echoes on ultrasound. However, they may also be hyperechoic or have a solid appearance resembling a hepatic tumor. ${ }^{1}$

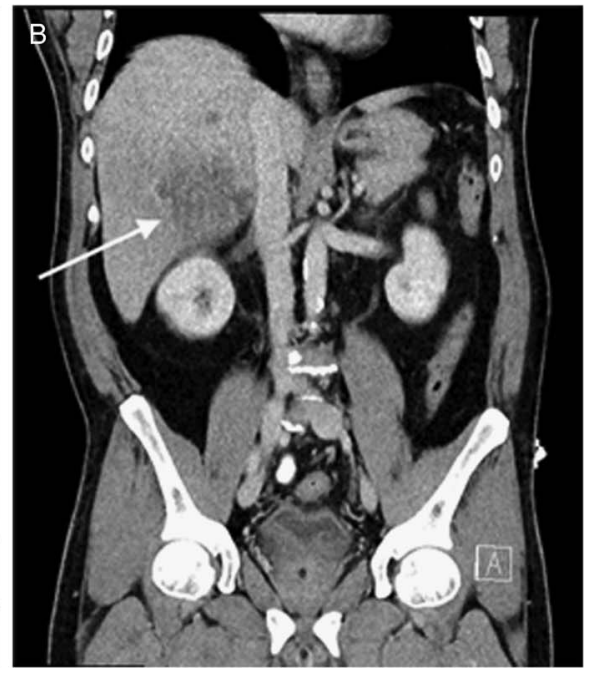

Figure 2. (A) Computed tomography scan image depicting the $7 \mathrm{~cm} \times 6 \mathrm{~cm} \times 6 \mathrm{~cm}$ liver abscess (arrow) in transverse orientation. (B) Coronal computed tomography scan image identifying the abscess (arrow) in the inferomedial portion of the liver adjacent to the inferior vena cava.

From the *Department of Emergency Medicine, St. Paul's Hospital, University of British Columbia, Vancouver, BC; †Department of Emergency Medicine, University of British Columbia, Vancouver, BC; and $¥$ Department of Emergency Medicine, Vancouver General Hospital, University of British Columbia, Vancouver, BC

Correspondence to: Dr. Diphile Iradukunda, 103 Hospital Dr., Saskatoon, SK S7N 0W8; Email: Diphile@ gmail.com

(C) Canadian Association of Emergency Physicians

CJEM 2018;20(5):802-803

DOI 10.1017/cem.2018.408 
The incidence of a liver abscess is around 2 to 3 per $100,000 .^{2-3}$ Risk factors for developing liver abscess include diabetes, male sex, middle age, and Asian descent. ${ }^{4-6}$ Common clinical manifestations include fever, chills, and abdominal pain. ${ }^{2-3,5-6}$ Laboratory investigations usually demonstrate elevated liver enzymes, elevated C-reactive protein, leukocytosis, and thrombocytopenia. ${ }^{2-3,5-6}$

The mainstay of treatment is with appropriate parenteral and subsequent oral antibiotics. However, percutaneous aspiration and even surgical intervention may be required for larger abscesses $>5 \mathrm{~cm}^{6-8}$

POCUS can rapidly identify the source of sepsis and lead to both an earlier diagnosis and definitive intervention compared with a standard clinical assessment. ${ }^{8}$ For patients with right upper quadrant pain, the literature demonstrates that emergency physicians can be trained to assess gallbladder pathology like cholecystitis with a high degree of accuracy. ${ }^{9-10}$ With experience, the biliary scan can be used to identify other pathology, such as liver abscess or biliary obstruction, that may direct the clinician to obtaining earlier consultative imaging and the initiation of an appropriate treatment plan.

\section{SUPPLEMENTARY MATERIAL}

To view supplementary material for this article, please visit https://doi.org/10.1017/cem.2018.408

Competing interests: None declared.
Keywords: Point of Care Ultrasound (POCUS), liver abscess, emergency medicine, gallbladder

\section{REFERENCES}

1. Gebel M (ed.) Ultrasound in gastroenterology and bepatology. Berlin, Germany: Blackwell Science; 2000.

2. Siu LK, Yeh KM, Lin JC, et al. Klebsiella pneumoniae liver abscess: a new invasive syndrome. Lancet Infect Dis 2012;12:881-7.

3. Yoon JH, Kim YJ, Jun YH, et al. Liver abscess due to Klebsiella pneumoniae: risk factors for metastatic infection. Scand 7 Infect Dis 2014;46:21-6.

4. Lederman ER, Crum NF. Pyogenic liver abscess with a focus on Klebsiella pneumoniae as a primary pathogen: an emerging disease with unique clinical characteristics. $A m \mathcal{7}$ Gastroenterol 2005;100:322-31.

5. Rahimian J, Wilson T, Oram V, et al. Pyogenic liver abscess: recent trends in etiology and mortality. Clin Infect Dis 2004;39:1654-9.

6. Liu CH, Tsai MJ. Invasive Klebsiella pneumoniae liver abscess syndrome. Ci fi Yi Xue Za Zhi 2016;28:86-7.

7. Chan DS, Archuleta S, Llorin RM, et al. Standardized outpatient management of Klebsiella pneumoniae liver abscesses. Int 7 Infect Dis 2013;17:e185-8.

8. Cortellaro F, Ferrari L, Molteni F, et al. Accuracy of point-of-care ultrasound to identify the source of infection in septic patients: a prospective study. Intern Emerg Med 2017;12:371-8.

9. Summers SM, Scruggs $W$, Menchine MD, et al. A prospective evaluation of emergency department bedside ultrasonography for the detection of acute cholecystitis. Ann Emerg Med 2010;56:114-22.

10. Ross M, Brown M, McLaughlin K, et al. Emergency physician-performed ultrasound to diagnose cholelithiasis: a systematic review. Acad Emerg Med 2011;18:227-35. 